\title{
Feedback control of the Marangoni-Bénard convection in a horizontal fluid layer with internal heat generation
}

\begin{abstract}
Feedback control is applied to the steady Marangoni-Bénard convection in a horizontal layer of fluid with internal heat generation heated from below and cooled from above. The analytical technique is used to obtain the close form analytical expression for the onset of Marangoni-Bénard convection when the lower boundary is conducting. The effects of feedback control are studied by examining the critical Marangoni numbers and wave numbers. It is shown that the critical Marangoni number decreases as the value of internal heat generation but the critical Marangoni number can be increased through the use of feedback control.
\end{abstract}

Keyword: Marangoni-Bénard convection; Feedback control; Internal heat generation 